\title{
Promoting Collaborative, Self-directed, Hands-on Learning in Engineering Design in Undergraduate and Graduate Teaching
}

\author{
Khosrow Farahbakhsh \\ School of Engineering, University of Guelph \\ khosrowf@uoguelph.ca
}

\begin{abstract}
The face of engineering education is rapidly changing as more emphasis is placed on a selfdirected, problem-based and design-driven approach. The School of Engineering at the University of Guelph has recognized the importance of engineering design education by introducing capstone design courses and encouraging incorporation of design in many senior-level courses. Two recent initiatives include inclusion of a studentled laboratory design project in the Mass Transfer Operations course (ENGG*3470) and a self-directed, problem-based approach to teaching a new graduate course in Pollution Prevention Engineering (ENGG*6790). Both courses placed a significant emphasis on "learning by doing" and importance of "self-directed learning". Both courses also encouraged the development of various design skills such as problem definition, information collection, collaboration, innovation, communication, life-cycle costing, etc. This paper provides insights on these two courses and the approaches used to ensure a collaborative, hands-on and self-directed learning experience for students.
\end{abstract}

Key words: Engineering design, laboratory design, problem-based learning, self-directed learning, collaborative learning

\section{Introduction}

The concept of collaborative leaning has been studied and practiced extensively over the past several decades. Various forms of collaborative learning such as team-based learning, cooperative learning, active learning, problem-based learning, etc. have been successfully implemented in the engineering education field. In attempting to discuss collaborative learning, it would be useful to establish a reasonably broad definition of the term. For the purpose of this paper, the definition presented by Michael Schrage is used. “...collaboration is the process of shared creation: two or more individuals with complementary skills interacting to create a shared understanding that none had previously possessed or could have come to on their own. Collaboration creates a shared meaning about a process, a product, or an event."

Collaborative learning therefore promotes establishing of teams of two or more individuals with complementary, but not identical, skills designed to create a shared understanding (learning) about a process or product. Collaborative learning should therefore be both active and interactive.

Bloom's Taxonomy defines six levels of instructional objectives: 1) knowledge, 2) comprehension, 3) application, 4) analysis, 5) synthesis and 6) evaluation [2]. Most instructors of engineering courses using conventional, purely lecture-based approaches will find it difficult to effectively achieve the above objectives in their courses. Others promote a more specific approach for effective teaching including formulating and communicating objectives, establishing relevance for course materials, balancing concrete and abstract information, and promoting active and cooperative learning [3]. The concept of problem-based learning places a significant emphasis on the above approach by defining specific problems for which students find solutions in an active and cooperative learning environment $[4,5]$. The challenge often remains, for especially new professors, as to which of many approaches would be most effective in the context of their teaching experience. General research in learning and knowledge translation in the context of international development has identified a simpler model that includes problem definition, solution identification, implementation and reflection. Often such a model is practiced in a multi-stakeholder learning platform where shared problems create a need for collaboration [6, 7]. Applying such a model, referred to at times as "learning alliances" to a classroom experience may provide a simple strategy for effective learning. 
The subsequent sections provide two examples of attempts in implementing such a collaborative learning model. The first example deals with a laboratory design and build project for an undergraduate engineering course. The second example explores the experience of incorporating such an approach within a graduate-level engineering course.

\section{The undergraduate experience - Laboratory design and build project}

Mass Transfer Operations (ENGG*3470) is a required third-year course for all Environmental Engineering students at the School of Engineering. This course provides students with an understanding of fundamental mass transfer concepts and their applications in the design and operation of mass transfer unit operation. The course was originally designed with no laboratory components. However, it was felt that student learning can be enhanced with the introduction of certain lab-based activities. The first attempt at inclusion of such activities involved design of a pilot-scale wet scrubber. All students were required to participate in some aspects of the design with individual tasks assigned to each student by the instructor. Although the experience proved beneficial, the logistics of guiding a class of 25 to 30 students to design and build a lab or pilot-scale equipment proved difficult. The new instructor of the course decide to modify the approach by facilitating a laboratory design and build project involving groups of up to five students. The project initially required groups of students to select one topic from among several topics provided by the instructor or choose a mass-transfer relevant topic for the lab-scale design. Topics included gas or liquid-phase adsorption, absorption (scrubbing), gas stripping, distillation, contaminant transport in soil, membrane separation, ion exchange, etc. Each group was then assigned the task of selecting a contaminant (or compound) for mass transfer; finding most effective analytical approach for measuring its concentration; designing, building and trouble-shooting lab-scale equipment; writing a laboratory manual and performing at least two sets of experiment and compiling a laboratory report. Based on the recommendations from the first group of students to attempt this exercise, the approach was modified to allow each group to also perform a selected number of laboratories designed by other groups. This required each group to prepare a one to two page summary of the lab including procedure for a simplified lab, and required analysis. Other groups would then perform the lab, answer the questions posed in the lab sheet(s) and hand the completed sheet to the graduate teaching assistant (GTA) for grading. Based on further recommendations from the students, the experimental design component evolved to include a series of milestones. Each group was required to submit a short 1 to three page report for each milestone (four milestones in total). For the first milestone, each group was asked to provide the GTA and instructor with a title, objective and overall approach for the experiment. The second milestone report was required to provide a more detail description of the experiment, proposed experimental setup and procedure and required analysis. The third milestone involved a 5 minute presentation during the tutorials with each group describing their setup with either actual demonstration (bringing the setup to the tutorial) or through pictures and movies. The final milestone was the submission of the laboratory manual and report as well as the shorten laboratory sheet that were to be used by the other groups performing the experiment. This arrangement was very helpful for ensuring that the student's limited time is efficiently used without unnecessary distraction. Sufficient feedback was provided to each group following the completion of each milestone. This process also required effective coordination between the instructor and the GTA. This was accomplished through weekly meeting with the GTA and other forms of communication as required.

The current grading scheme for the course is as follows:

$\begin{array}{ll}\text { Experimental design: } & 35 \% \\ \text { Four short labs: } & 15 \% \\ \text { Quizzes (three) } & 15 \% \\ \text { Final exam: } & 35 \%\end{array}$

\subsection{The rationale for student-led experimental laboratories}

It is common for introductory mass transfer courses to include a number of laboratory experiments. The purpose of such experiments is to provide the students with hands-on training in operating mass transfer units and collection and analysis of mass transfer related data. Although such experiments have merit, the approach suffers from several limitations.

1. The experimental design, setup and instrumentation are normally put together without input from students and as such the students do not gain experience in design, setup, 
and trouble shooting of laboratory and pilot-scale facilities.

2. Detailed experimental procedures, including data collection, monitoring and often analysis, are provided to the students in advance of the experiments. Students therefore, do not sharpen their skills in designing laboratory experiments.

3. The students, in general, are not provided with an opportunity to enhance their research skills including literature review, proposal development, and development of research methods.

4. Few students take ownership of the experimental work and little sense of pride of the final product is engendered.

Another aspect of traditional laboratory experiments is that they place considerable burden on the departmental resources and require sufficient space and equipment and extensive involvement of laboratory technicians. Small programs with limited resources will find the implementation of such experimental laboratories overtaxing. A lack of resources (laboratory space and technician time) was one reason for incorporating the student-led experimental laboratories in the third-year mass transfer course.

Inclusion of the student-led experimental laboratories in the mass transfer course was also a natural extension of the underlying engineering education philosophy of the School of Engineering at the University of Guelph. A great deal of emphasis is placed on incorporating design in as many engineering courses as possible. To complete their degrees, all students take four design courses (one per year) culminating with the capstone design course in the final year. In addition, design is integrated into a number of program specific courses. For Environmental Engineering students they have significant design experiences incorporated in at least five other courses.

\subsection{Description of some of the experimental laboratories}

As indicated earlier, up to nine experimental laboratories (depending on the number of students each year) were designed by the students in this course. A brief description of each experimental laboratory is presented below.

\section{Absorption (scrubbing)}

This experiment involved the design of a packed column to remove chlorine gas or $\mathrm{CO}_{2}$ from an air stream. Packing material were plastic beads which filled a $38 \mathrm{~mm}$ plastic column. The impact of packing height, gas and liquid flow rates on the removal of chlorine or $\mathrm{CO}_{2}$ was evaluated.

\section{Gas stripping}

This lab investigated the removal of ammonia from water using a $38 \mathrm{~mm}$ plastic packed column. The impact of $\mathrm{pH}$, packing height, gas flow rate in stripping ammonia was evaluated.

\section{Activated Carbon Adsorption (liquid phase)}

Removal of methylene blue from water using three different types of activated carbon was investigated. The experiment involved conducting adsorption isotherm tests to select the most effective carbon and preparation of breakthrough curves for the selected carbon. A schematic of their apparatus is shown in Figure 1.

\section{Activated carbon adsorption (gas phase)}

This experiment involved removal of toluene from air using a $25 \mathrm{~mm}$ diameter activated carbon column. The experiment involved conducting adsorption isotherm tests and preparation of breakthrough curves for the activated carbon-toluene system.

\section{Membrane separation (liquid phase)}

This experiment involved evaluation of the impact of temperature and fouling on membrane flux and transmembrane pressure. Figure 2 shows the schematic of the setup for this project.

\section{Ion exchange}

The purpose of this experiment was to remove hardness (approx. $400 \mathrm{mg} / \mathrm{l}$ as $\mathrm{CaCO}_{3}$ ) from tap water using ion exchange. Zeolite was used as the ion exchange resin and sodium chloride was used to regenerate the resin. The experiment evaluated the overall performance of the system for the removal of total, calcium and magnesium hardness. A schematic of the setup is shown in Figure 3. 


\section{Distillation}

This experiment evaluated the effect of column height on the removal of methanol from methanolwater system using distillation. In addition the diffusion coefficient of methanol in air was measured and compared with published values. Plate 2 shows the setup for this experiment.

\section{Chlorination of water}

This experiment involved the production of chlorine gas through electrolysis of water with high concentration of sodium chloride, collection of the chlorine gas and transfer of the gas to water using a venturie eductor. The students designed and produced the eductor from ABS using a newly purchased 3-D printer.

Some of the schematics and pictures of various projects are shown below.

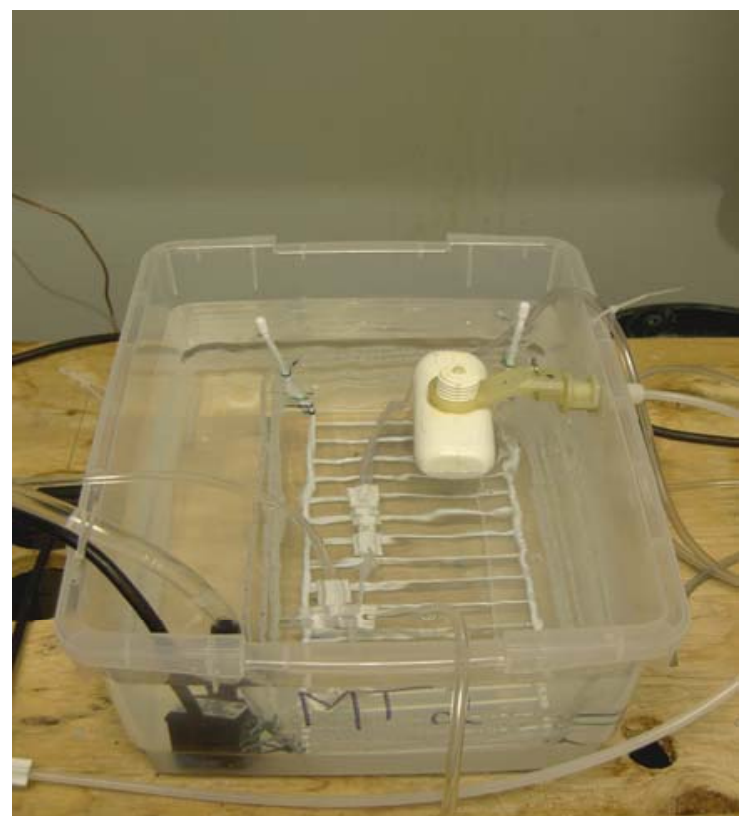

Figure 1. experimental setup for the Removal of VOCs using dense phase non-porous membranes.

\subsection{Collaborative aspects of the project}

The laboratory design project, by its very nature, forced the students to collaborate in a variety of ways with each other, their GTA, other graduate students, and laboratory technicians. Each group had to identify the nature of the problem the laboratory design was to address. This required extensive selfdirected research and group consultation. Each group had to also determine how to design and build the laboratory setup and in doing so they relied on group consultation as well as collaboration with the machine shop and laboratory technicians. In some cases, the groups found consultation with graduate students researching similar topics very useful. The problem definition and solution identification for the laboratory design project therefore was guided by a consultative process that reduced the gap between undergraduate students, graduate students and laboratory technicians.

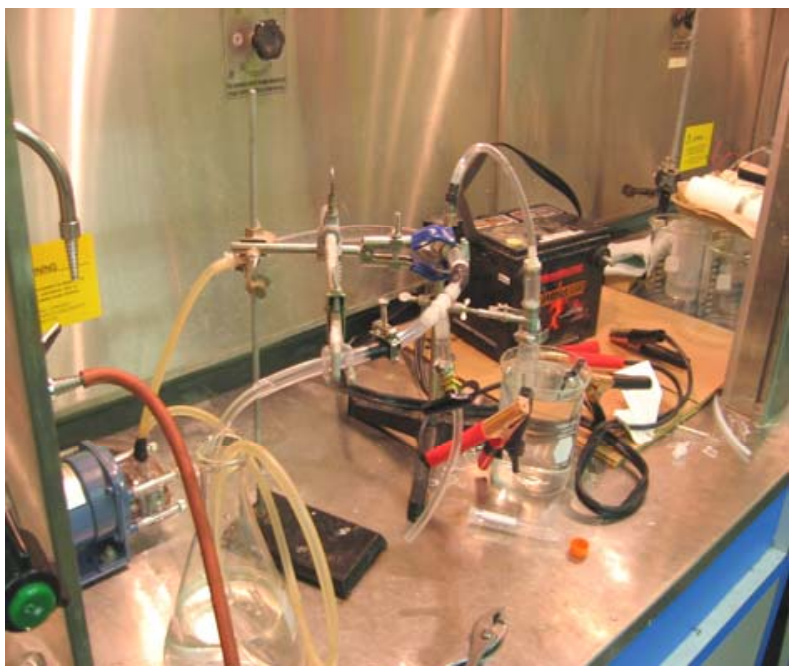

Figure 2. Setup for chlorination experiment

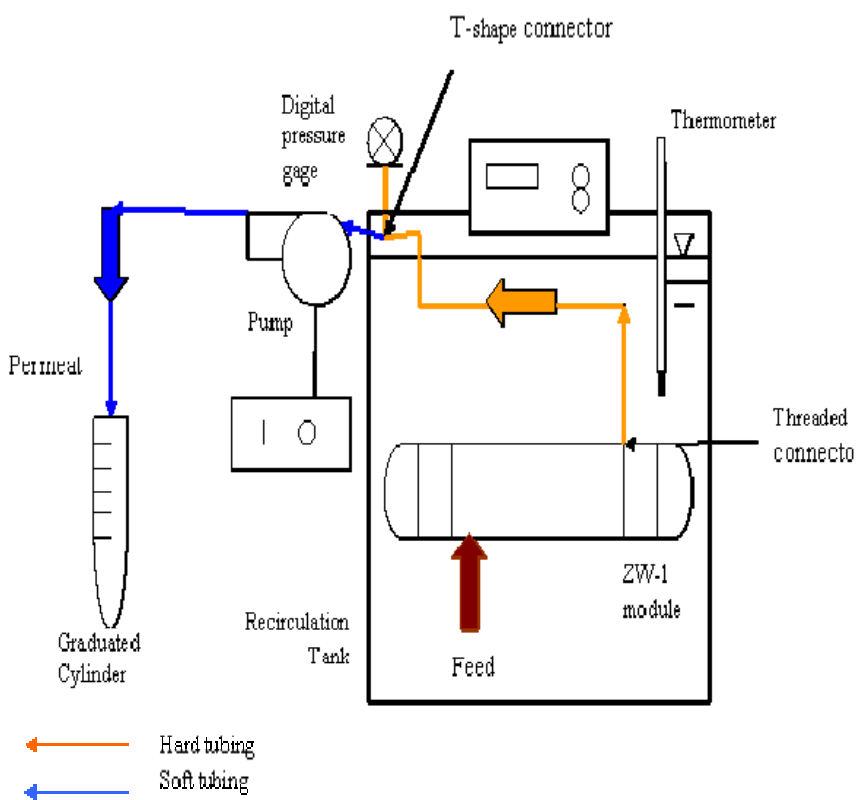

Figure 3. The schematic of membrane flux experiment 


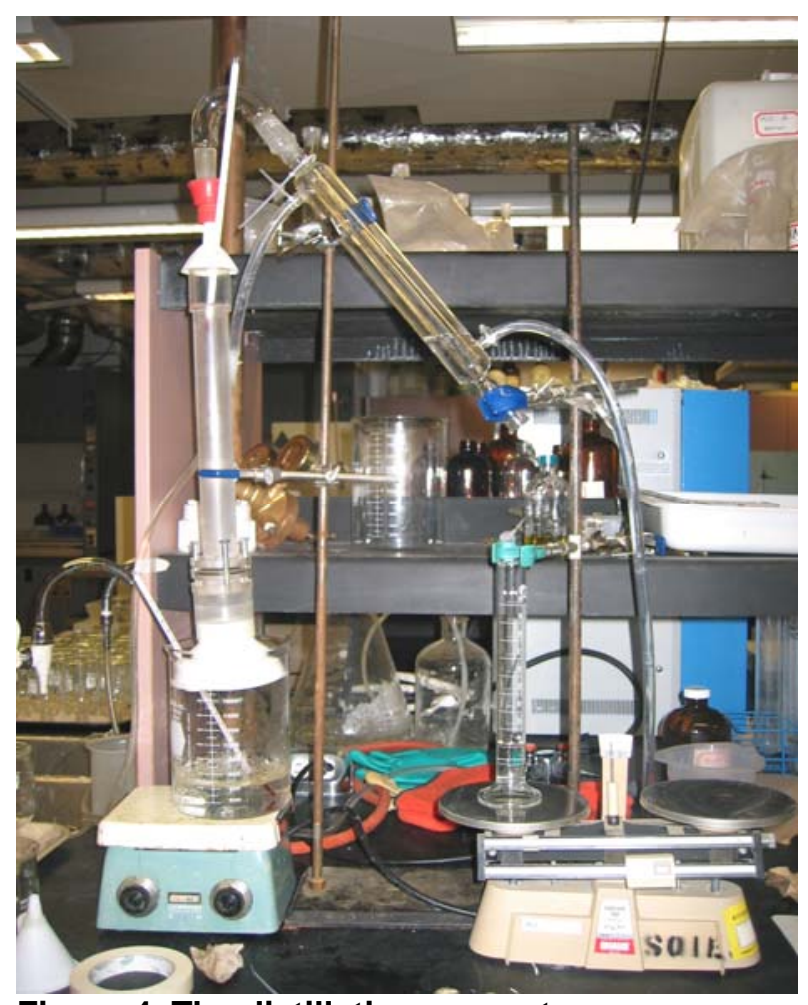

Figure 4. The distillation apparatus

The action or implementation component of the project was also an iterative, collaborative process guided by frequent reflections when the built prototype did not performed as expected. Performing the experiments and preparing the laboratory manuals and reports were also collaborative in nature as the groups were given relative freedom in how to present their findings. Finally, great deal of collaboration and coordination was required between groups and with laboratory technicians to ensure that short labs are properly scheduled.

\section{The graduate experience - preparing pollution prevention programs}

Pollution Prevention Engineering (ENGG*6790) was offered for the first time in winter of 2007. The objective of the course was to facilitate development of skills in conducting a pollution prevention audit and preparing pollution prevention programs among engineering graduate students (primarily from Environmental Engineering and Water Resources Engineering programs). During the development phase of the course it became increasingly clear that active involvement of the industry should be a key ingredient in developing such a course. After contacting a number of industries in Guelph, four agreed to participate in the program. All four were large manufacturing plants and included a pharmaceutical manufacturer, a manufacturer of automotive cooling devices, another automotive part manufacturer, and a manufacturer of chain saw components.

\subsection{Class structure}

It was clear from the onset that such a course cannot be effectively taught in a typical lecture-based classroom. Driven by the instructor's research interests in collaborative decision-making for sustainable water management, the class was structured to promote participatory learning and peer teaching. The 3-hour lecture period was primarily an opportunity for the students to report on their findings during the week, presenting the challenges they were facing and seeking advice from their peers and the course instructor. Each group was given 15 minutes to present their findings followed by a 15 minute discussion. The remainder of the lecture was used by the instructor to provide additional insight and information based on the nature of the discussion that was resulted from each presentation. This meant that, for the most parts, there were no prepared lecture notes. A large body of information in the form of reports and other publications was posted by the instructor and at times other students on the course Web-CT site and the students were asked to read and apply certain information to their pollution prevention work for tat week. For example, the concept of pinch analysis was first introduced briefly by the instructor and the students were then asked to use the documents posted on the WebCT and apply the pinch method to their respective industry for water or energy analysis. During the subsequent lecture the students presented the results of their pinch analysis and the challenges they had in applying the method to their particular problem. This then provided an opportunity for the instructor and other students to help clarify certain aspects of pinch analysis. This ensured that the students learned and retained the information and insight far more effectively than through conventional lectures by the instructor.

A unique aspect of the course was the presence of a Ph.D. candidate from a sociology program who was conducting research on innovative ways engineering learn and translate knowledge. The Ph.D. candidate attended all the lectures but did not participate in the pollution prevention related discussion. However, at times he raised question from the sociological point 
of view that generated interesting response form the students. The Ph.D. candidate made a presentation to the students on his findings during the final lecture.

The grading scheme for this course was as follows:

$\begin{array}{ll}\text { Class presentations: } & 40 \% \\ \text { Class participation: } & 15 \% \\ \text { Final report: } & 45 \%\end{array}$

The reason the final report was assigned a lower percentage of the grade than the class presentation and activities was to emphasis the importance of the process of collaborative learning. This was discussed during the first lecture and students were generally supportive of the decision.

\subsection{Industry's involvement}

Meaningful industry involvement was essential in the success of this course. The course instructor met with the industry's representatives prior to the commencement of the course and provided them with detailed information on the course, the expected outcomes and the expectations regarding the industry's contribution. Several areas suitable for pollution prevention were also identified during these meetings.

The industry's involvement in this course was driven by two main factors. Each industry has been interested in conducting pollution prevention program targeted to certain areas such as energy efficiency improvement or waste reduction. The industries saw this course as an opportunity to initiate these programs. In addition, the industries were genuinely interested in providing an opportunity for the students to learn and sharpen their skills.

Each group was asked to meet with the industry's representative once per week. These meetings were typically conducted at the plants locations and targeted at identifying areas suitable for conducting pollution prevention programs and specifying, with clarity, the objectives of the pollution prevention program. Each group, in collaboration with the industry's representatives, prepared a set of milestones and targeted completion dates. This ensured that both the students and the industry were committed to ensuring timely completion of tasks as the limited duration of the course could not permit long delays.

\subsection{Collaborative aspects of the course}

The entire course was conducted with the notion of collaboration in mind. The students' involvement with the industry has mutual benefits for both groups. Students gained first hand insight as to challenges and opportunities of conducting pollution prevention programs. The industries on the other hand, were benefited from student's expertise and were enabled to explore pollution prevention in areas where their limited time and/or resources would have not otherwise permitted.

The 3-hour weekly lecture period was another opportunity for collaborative learning. There were many lively discussions and as the course proceeded, the students began to feel more confident in providing insight and suggestions to their peers. Having students with a wide range of expertise also allowed the problems to be synthesized from diverse angels. The role of the instructor was primarily one of facilitation. At times short lectures were provided and often opportunities for impromptu lectures arose from students' discussions.

The process of report preparation was also collaborative in nature. Each group was asked to review the draft report of another group and provide both written and oral feedback. The oral feedback during the lecture period provided yet another opportunity for discussion and peer teaching. The instructor then reviewed all reports and provided feedback on how to present information to industrial clients so as to promote action.

Each group hand delivered the final report to the clients and in some cases the groups were asked to make a formal presentation to the industry's representative. The instructor has remained in dialogue with the industry's representative to monitor the implementation of the recommendations from the pollution prevention reports.

\section{Discussion}

A simple collaborative model for graduate and undergraduate engineering teaching was presented. The model focuses on implementing certain elements of collaborative learning into each course. These elements include problem definition, solution identification, implementation and reflection. The key participants in such a model are students as well as other relevant stakeholders such as the instructor, laboratory technicians, other student groups, and the industry, to name a few. Many elements of other 
innovative teaching models such as problem-based learning, cooperative learning, team-based learning, etc. are inherent in this collaborative learning model. The outcome of collaboration in the above two examples was to develop a product or a process through shared learning. The proposed model can be implemented in classed of various sizes and can be tailored to fit various classroom settings.

An important consideration in implementing such a model is the gradual introduction of various elements into the course. The various elements of collaborative learning, particularly reflection must also be exercised as the course is being modified to implement the collaborative learning model. Especial attention must be paid to student's feedback and the instructor must exercise flexibility and openness and facilitate student's feedback throughout the course.

\section{Acknowledgements}

The author wishes to acknowledge the assistance of Ms. Joanne Ryks and Mary Leunissen in helping the students with their experimental work. The author also wishes to acknowledge the fortitude and encouragement of all his students who patiently endured his, some times disorganized, attempts to improve the course. The financial support to attend the conference from the NSERC Design Chair in Environmental Engineering at the University of Guelph is also greatly appreciated.

\section{References}

[1] Shrage, M. No More Teams: Mastering the Dynamics of Creative Collaboration, Currency Doubleday, 1995, p.31.

[2] Bloom, B.S. and Krathwohl, D.R. Taxonomy of Educational Objectives. Handbook 1: Cognitive Domain. Addison-Wesley, New York, 1984.

[3] Felder, R.M.; Woods, D.R.; Stice, J. E.; Rugarcia, A. The Future of Engineering Education II. Teaching Methods that Work. Chem. Engr. Education, 34(1), 26-39 (2000).

[4] Woods, D.R. Problem-based Learning: Helping Your Students Gain the Most from PBL. Woods Publishing, Waterdown, 1997. Distributed by McMaster University Bookstore, Hamilton $\mathrm{ON}$, and available on-line at $<$ http://chemeng.mcmaster.ca/pbl/pbl.htm>.

[5] Engel, C.E. "Not Just a Method but a Way of Learning." Chapter 2 in The Challenge of Problem-based Learning, D.J. Boud and G. Feletti, eds., Kogan Page, London, 1991.
[6] IRC - International Water and Sanitation Centre - BUS Handbook, Section 3 - Learning Alliances. Available at http://www.irc.nl/page/27734.

[7] Moriarty, P.; Fonseca, C.; Smits, S.; and Schouten, T. (2005). Background Paper for the Symposium: Learning Alliances for scaling up innovative approaches in the Water and Sanitation sector. IRC International Water and Sanitation Center.

http://www.irc.nl/content/download/16138/208040/file/Bac kground_paper_symposium_.pdf 